\title{
Analysis of the Damage of Boiler Bottom Slope Pipe in Steam Power Plant
}

\author{
Rusnaldy, Mohammad Tauviqirrahmana, Norman Iskandar ${ }^{b}$ \\ a,b Department of Mechanical Engineering \\ Engineering Faculty \\ University of Diponegoro, Semarang. \\ JI. Prof. Soedarto, SH., UNDIP,Tembalang \\ Semarang 50275 \\ Email: rusnaldy@undip.ac.id
}

\begin{abstract}
Bottom slope pipe on boiler system in one of steam turbine power plant had been damaged. The damage was dent on the outside of pipe and was suspected as a result from foreign object impact from outside pipe. From chemical composition examination and hardness test, it showed that nothing wrong with the selection of the pipe. From visual inspection, there is no other factor such as corrosion or deposit formed inside the pipe was found. Analysis of cause of damage in the pipe then further conducted by observing microstructure and hardness value on the area which experience damage. Simulation on mechanical and thermal analysis had been conducted to determine what and origin of foreign object which impacted on pipe and the temperature when it was happened. From the observation, of microstructure and hardness test showed that pipe had been experience plastic deformation on temperature under recrystallization temperature. Simulation results also confirmed that the initial assumption on cause of pipe damage from foreign object, which is small size slag that felt from very high location so that caused high speed impact on pipe. Thermal analysis result also supporting the suspicion that slag impact on pipe was occurred in temperature under recrystallization of pipe material.
\end{abstract}

Keywords: Bottom Slope Pipe; Falling Slag; Steam Power Plant; Damage

\section{INTRODUCTION}

Bottom slope pipe on boiler system had been experienced damage in form of dent caused by plastic deformation (see Figure 1). The pipe is one located in lower furnace area on boiler system. Inside bottom slope pipe is fluids in liquid phase to be evaporated. On the outside of pipe, there is available pulverized fine coal. This fuel then blown into furnace and then ignited with the fire and combusted with other fuel. Additional air for combustion was supplied into furnace until perfect combustion occurred.

In coal fuelled steam turbine power plant, soot blower is a very important device because has function to clean pipes on Heat Recovery Area (HRA) which is area of superheater, economizer, and reheater of sticked waste/slag. Exhaust combustion gas in furnace was dubbed as flue gas. On flue gas produced by combustion, it contained a lot of ashes. Liquid ashes which contained in flue gas will stick and freeze when flue gas reach convection heated area in HRA. Sediment liquid ashes could become very hard and was dubbed as bird nesting. Meanwhile, fly ash, solid ashes which flew in following the flow of flue gas will sticked on the wall of pipe element which will decrease efficiency of heat transfer. In process of coal fire, pipe will be exposed to combustion heat radiation so that liquid fluid will evaporate and will be streamed to steam drum. 




Figure 1.1 Pipe with damage (shown by arrow) caused by impact of foreign object

When observed on its operating condition, the damaged bottom slope pipe was operated on high temperature range and pipe had been in operation for at least 10 years. Other than thermal aspect, there was another aspect which contributes to the damage of the pipe. The position of bottom slope pipe which was situated on the area of slag falling makes possible to experience impact from solid material of combustion residue. The fall of slag caused possible impact on the pipe. Such possibility was examined to analyze the damage on the bottom slope pipe in this research.

\subsection{Operating History and Conditions}

From gathered information, the pipe had been operated for about ten (10) years since 2004. The pipe never been replaced because the operational life was designed for thirty (30) years or more. The type of material for pipe was SA-210-C where properties and specific data were presented in Table 1 with dimensional data for the pipe was given in Table 2. In operating condition, radiation exposure on the outer side of pipe was heat with temperature of $1200^{\circ} \mathrm{C}$ and inside the pipe flow water on temperature of $70^{\circ} \mathrm{C}$.

Table 1.1 Material of Pipe Properties (Source: ASME Section II Part. D [1])

\begin{tabular}{ll}
\hline \multicolumn{1}{c}{ Physical and Mechanical Properties of Pipe } & Value \\
\hline Tensile strength $(\mathrm{MPa}) \min$ & 485 \\
\hline Yield strength $(\mathrm{MPa}) \min$ & 275 \\
\hline Elongation $\mathrm{GL}=2 \mathrm{in} \min$ & 0,30 \\
\hline Young Modulus $(\mathrm{MPa})$ & 198.000 \\
\hline Isotropic thermal conductivity $\left(\mathrm{W} / \mathrm{m}^{\circ} \mathrm{C}\right)$ & 60,5 \\
\hline Specific heat $\left(\mathrm{J} / \mathrm{kg}^{\circ} \mathrm{C}\right)$ & 434 \\
\hline
\end{tabular}

Table 1.2 Dimension of the Pipe

\begin{tabular}{ll}
\multicolumn{1}{c}{ Measured Dimension } & \multicolumn{1}{c}{ Value } \\
\hline Outer Diameter $(\mathrm{OD})(\mathrm{mm})$ & 57,30 \\
\hline Thickness $(\mathrm{mm})$ & 6,50 \\
\hline
\end{tabular}

\section{Methodology}

The condition of bottom slope pipe as received could be seen in Figure 1. The visual inspection was conducted to detect the location of damage on the pipe and the prediction of the cause of damage.

Chemical composition test and hardness test on pipe material also was conducted. The test has an objective to give proof there was no wrongdoing in selecting the used pipe material. To give proof that damage was caused by plastic deformation in nature, the microstructure examination on the region of defect and region outside defect area. Also hardness test was conducted on the area experienced plastic deformation.

The simulation of the cause of damage on pipe was also conducted to support the prediction that damage was caused by foreign object impact which fall into the pipe. From 
Figure 1.1, it was seen that theoretically defect was occurred when plastic deformation occurred. This type of deformation was occurred when von Misses stress reach the value of material yield stress. The high value of stress in this case was predicted caused by foreign object fall into the pipe from certain height in furnace with relatively very high velocity. The occurred stress caused by fall of foreign object may be compounded by already available thermal load. Relatively high thermal gradient was caused by temperature difference between outside and inside of pipe. Very high temperature produced by flue gas outside pipe and high operational hours of pipe (about 87,600 hours) caused decreasing of quality of the material itself. In other words, when foreign object fall into pipe, the pipe was not in best condition to hold plastic deformation. These hypotheses will be proved by simulation on the cause of damage.

\section{ResULTS AND Discussion}

\subsection{Visual Inspection}
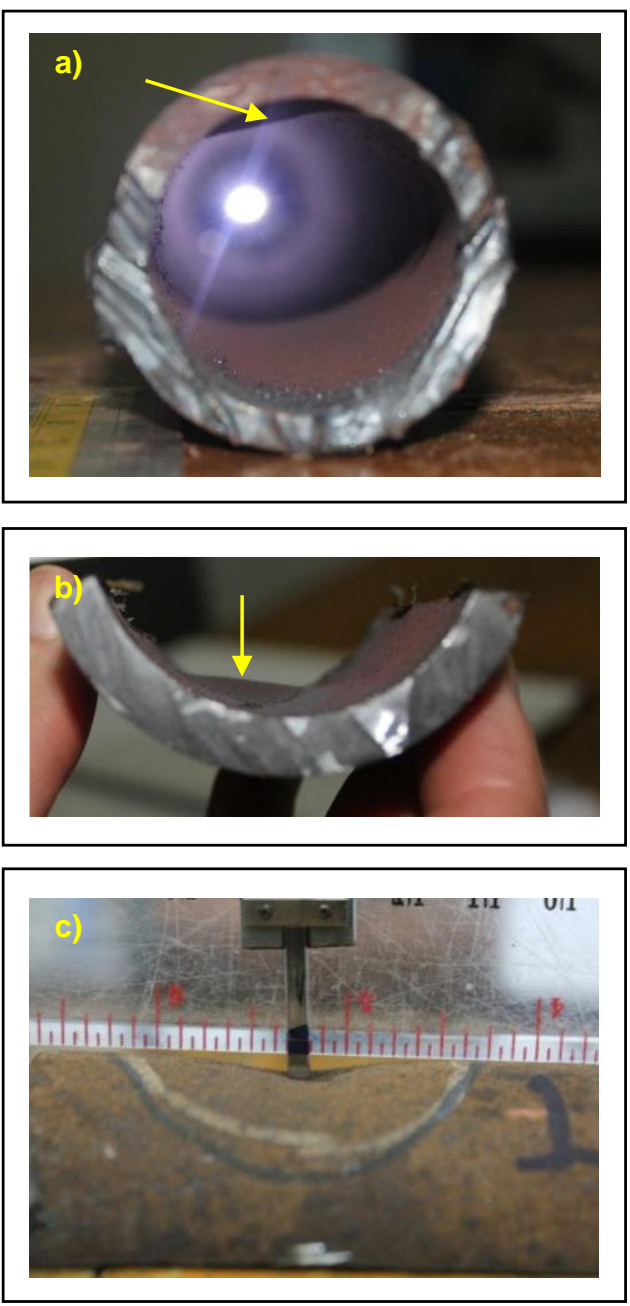

Figure 3.1 Visual Inspection on Damage Pipe

The photograph of damaged pipe can be seen in Figure 3.1. The feature of inside pipe (Figure 3.1a) showed the part of pipe deformed inside (dark area shown by the arrow). Other side was in good condition. No sign of excessive corrosion and deposit. The arrow showed feature of inside part of pipe which plastically deformed, but no crack 
or hole shown in this area (Figure 3.1b). From measurement, the depth of biggest measured plastic was $3.10 \mathrm{~mm}$ (Figure 3.1c).

From results of visual inspection, some issues were outlined as follows:

1. Defect caused by plastic deformation was found on the pipe. The plastic deformation likely was caused by impact of foreign object from outside of pipe.

2. Excessive deposit was not found inside the pipe.

3. Damaged related to corrosion was not found inside pipe, such as pitting corrosion, caustic corrosion and other type of corrosion which endangered the pipe, like common damaged inside the pipe of boiler [2, 3].

4. Crack and hole was not found inside the pipe in area experience plastic deformation.

\subsection{Chemical Composition Examination and Hardness test of Pipe Material}

The test has an objective in proofing that nothing wrong in selection of pipe material. Specification of pipe material used in experiment was SA-210-C. The result of chemical composition examination and hardness test was compared with ASTM A210 Standard "Standard Specification for Seamless Medium-Carbon Steel Boiler and Superheater Tubes" [4].

The result of chemical composition test and hardness test and standard specification of material was given in Table 3.1 and 3.2.

\begin{tabular}{|c|c|c|}
\hline Elements & Standard (\%) & As Measured (\%) \\
\hline C (maks) & 0,35 & 0,356 \\
\hline $\mathrm{Mn}$ & $0,29-1,06$ & 0,808 \\
\hline $\mathrm{P}$ (maks) & 0,035 & 0,037 \\
\hline S (maks) & 0,035 & 0,014 \\
\hline $\mathrm{Si}(\mathrm{Min})$ & 0,1 & 0,229 \\
\hline
\end{tabular}

Table 3.2 Hardness Test Result

\begin{tabular}{|l|l}
\hline Standard (HRB) & As Measured (HRB) \\
\hline Maks. 89 & $84,8-89,7$ \\
\hline
\end{tabular}

The conclusion drawn from the test of pipe material was "selected pipe material in accordance with predetermined specification".

\subsection{Microstructure Analysis and Hardness on Defect Area}

In order to proof the occurrence of plastic deformation on defect, microstructure analysis on defects area was conducted (location 2) and on area outside defect area (location 1 and 3 ) in Figure 3.1. The hardness test also was conducted on the area experienced plastic deformation. The Result of microstructure photograph was depicted in Figure 3.2 and 3.3.

Photograph of microstructure outside defect area (free from defect area) was given in Figure 4. From the structure, it can be shown that ferrite and pearlite phase was on the material. Microstructure photograph of defect area can be seen in Figure 5. The grain in defect area experienced stretching which indicate plastic deformation was occurred. Plastic deformation also occurred on temperature below recrystallization (cold forming).

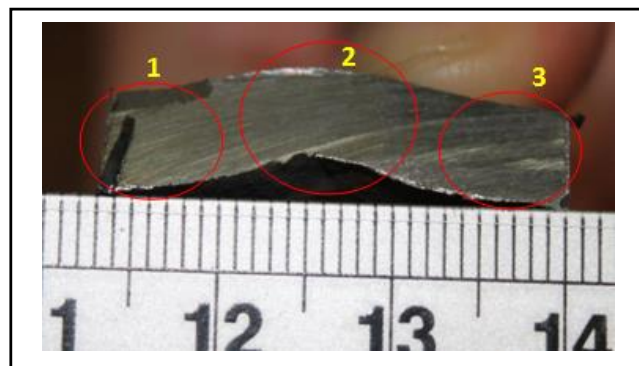

Figure 3.1 Observation Area of Microstructure and Hardness Test 




Figure 3.2 Microstructure of Area free from Defect

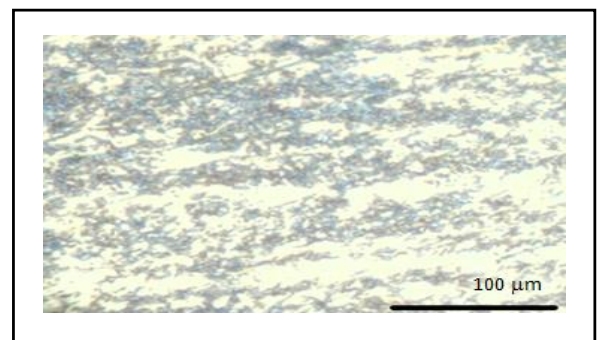

Figure 3.3 Photograph of Microstructure of Defect Area

The result of hardness test was presented in Table 3.4.

Table 3.3 Result of Harness Test in Area around Defect and Free from Defect

\begin{tabular}{lc}
\multicolumn{1}{c}{ Location } & HRB \\
\hline Free from defect & $84,8-89,7$ \\
\hline Area 1 & $91,1-93,4$ \\
\hline Area 2 & $95,9-96,0$ \\
\hline Area 3 & $92,0-92,5$ \\
\hline
\end{tabular}

From analysis of microstructure photograph and hardness test in the area around defect could be concluded as follow:

1. Defect was occurred by plastic deformation and initiated by foreign object impact from outside pipe. The impact occurred on temperature under recrystallization (cold forming).

2. From the result of hardness test, it supported the hypothesis where hardness value on defect area higher that free of defect area. Increase of hardness was a proof on plastic deformation in cold forming condition on defect area.

\subsection{Simulation Results}

Figure 6 showed the sketch of "defect" with dimension of real measurement dimension on the pipe. Based on the sketch, the foreign object fall into pipe and causing defect on pipe was simulated by employing finite element based computer software to acquire detail body of foreign object which consisted of dimension, volume, and mass [5]. By simulation, the prediction of impact speed of foreign object to pipe also was simulated.



Figure 3.4 Sketch on Pipe Defect, Top View (left), Side View (right) (dimension in mm) 
In computer simulation, foreign object was assumed in shape of polygon modeled in various dimension. The result of simulation showed that foreign object dimension most imitate defect shape on pipe described in Figure 6 as the one with thickness of $2 \mathrm{~mm}$, with length and width $16.96 \mathrm{~mm}$ both. From simulation results, it can be concluded that the condition of foreign object likely to fall into pipe was in volume of $575.28 \mathrm{~mm}^{3}$, with mass of $4.5 \mathrm{gram}$, and speed of impact of $26 \mathrm{~m} / \mathrm{s}$ (or equals to free fall from $34.5 \mathrm{~m}$ high). It means that the foreign object felt into pipe even though has relatively small size but able to make defect on pipe (because of plastic deformation) when the object felt from relatively high altitude. The speed of impact caused by gravitational acceleration is function of height. Table 6 showed the prediction on fallen foreign object.

Table 3.4 Detailed Prediction of Foreign Object

\begin{tabular}{ll}
\hline \multicolumn{1}{c}{ Parameter } & \multicolumn{1}{c}{ Value } \\
\hline Volume $\left(\mathrm{mm}^{3}\right)$ & 575,28 \\
\hline Mass $(\mathrm{gram})$ & 4,5 \\
\hline Dimension (length $\mathrm{x}$ width $\times$ thick) $(\mathrm{mm} \times \mathrm{mm} \times \mathrm{mm})$ & $16,96 \times 16,96 \times 2$ \\
\hline Speed of Impact $(\mathrm{m} / \mathrm{s})$ & 26 \\
\hline
\end{tabular}

Figure 3.5 showed the distribution of von Misses stress just after foreign object hit the pipe with certain speed. Based on the contour, it can be concluded that maximum von Misses stress was $274 \mathrm{MPa}$. If the value of stress was compared with yield strength $\left(\sigma_{y}\right)$ of initial design specification $(275 \mathrm{MPa})$, theoretically the pipe was not experienced plastic deformation. But, in fact pipe was plastically deformed caused by impact (see Figure 8). Likely, the impact was occurred on high temperature condition but still below recrystallization temperature. Increasing of temperature lowered value of yield strength. The operational life of pipe which is relatively long (around 87.600 hours) and exposed to high temperature gases also give likely cause of lowering of the strength since the yield strength of material is a function of temperature.

On simulation, the pipe was conditioned in exposure of radiation from combusted gas on $1200{ }^{\circ} \mathrm{C}$ in accordance with real condition. Based on contour of temperature distribution in the pipe (Figure 9), the temperature in the surface of pipe still in ranged of $100{ }^{\circ} \mathrm{C}$, which means far from recrystallization temperature of material. Therefore, plastic deformation caused by foreign object impact was occurred in cold forming condition. This result was in accordance with previous metallurgical analysis.



Figure 3.5 Distribution of von Misses stress (in MPa) right after foreign object impacted on pipe 


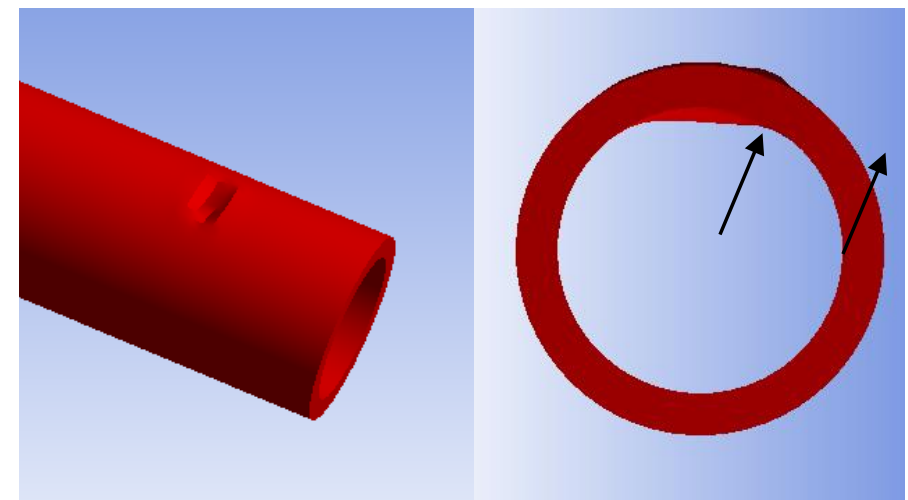

(a)

(b)

Figure 3.6 Deformation on pipe, (a) isometric view, (b) front view (Note: Arrow showed plastic deformation in the shape of indentation inside pipe).

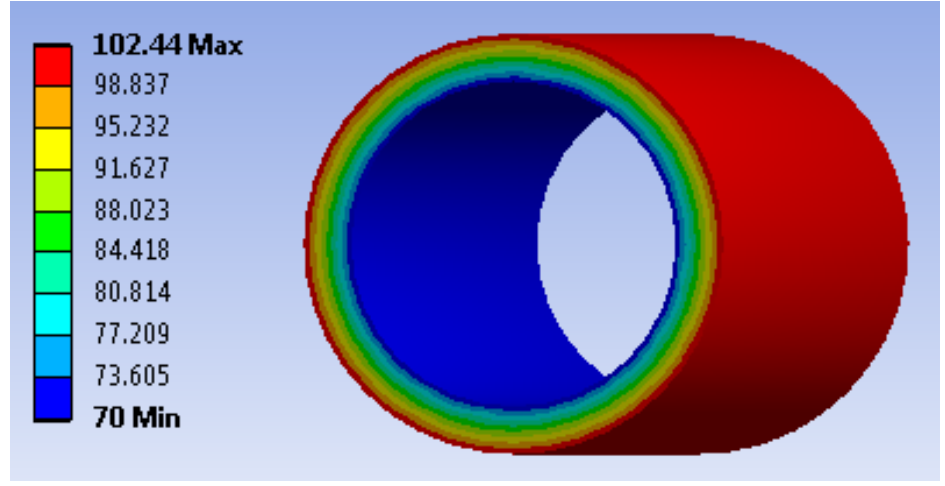

Figure 3.7 Temperature Distribution in Pipe Caused by Thermal Load (inº).

\section{Conclusion}

From the analysis, it can be concluded that:

1. The damage of bottom slope pipe was caused by falling slag impact. The slag was small in dimension and felt from relatively high location so that caused high impact speed causing plastic deformation on pipe.

2. Occurred plastic deformation was proved by microstructural analysis and hardness test on defect area and simulation.

3. Thermal analysis results was supported the statement that impact was occurred below recrystallization temperature of material.

4. Plastic deformation which occurred was not caused hole or crack to the pipe.

\section{REFERENCES:}

[1] ASME Boiler and Pressure Vessel Code. Section II - Materials and Specifications. USA; 2013.

[2] Port, Robert, R, D., Herro, M, H. The NALCO Guide to Boiler Failure Analysis. Nalco Chemical Company. McGraw-Hill Inc. 1991.

[3] ASM Handbook. Vol. 11: Failure Analysis and Prevention. ASM International: USA; 2004.

[4] ASTM. A210. Standard Specification for Seamless Medium Carbon Steel Boiler \& Superheater Tubes. ASTM International: USA; 2001.

[5] ANSYS Workbench Version 12.0, ANSYS, Inc. Southpointe 275 Technology Drive Canonsburg, PA 15317. 